Orissa Journal of Commerce

Vol. 42, Issue 1, Jan-March 2021

ISSN: 0974-8482

(c) OJC India. All Right Reserved

URL : www.ojcoca.org

DOI: https://doi.org/10.54063/ojc.2021.v42i01.08

\title{
Study on the Satisfaction Level of the Account Holders under Pradhan Mantri Jan Dhan Yojana Scheme
}

\author{
Sudeepta Raha ${ }^{1 *}$ and Parag Shil ${ }^{2}$ \\ ${ }^{1}$ Research Scholar, Department of Commerce, Assam University, Silchar, Assam. E-mail: sudeeptaraha@gmail.com \\ ${ }^{2}$ Professor, Department of Commerce,Assam University, Silchar, Assam.E-mail:drps007.aus@gmail.com \\ ${ }^{*}$ Corresponding Author
}

To cite this paper

Raha, S., \& Shil, P. (2021). Study on the Satisfaction Level of the Account Holders under Pradhan Mantri Jan Dhan Yojana Scheme. Orissa Journal of Commerce. 42(1), 105-115.

Keywords

Account holders, Banking services, Financial inclusion, Financial literacy, Satisfaction.

JEL Classification C83, C88, D14, G21, I38
Abstract: The paper intends to understand the satisfaction level of the account holders under the Pradhan Mantri Jan Dhan Yojana (PMJDY) scheme of Assam Gramin Vikash Bank (AGVB) in Cachar District. An Interview schedule has used to collect data from 265 respondents, subsequently computed through IBM SPSS Statistics Version 21 and MS Excel software. A protocol interview with 6 experts followed by a pilot survey with 40 respondents has executed primarily to examine the validity of the questions. The tools of analysis such as tabulation, graphs, percentage, median have used; Mann-Whitney $U$ test and Kruskal Wallis $\mathrm{H}$ test have performed to test the hypothesis considered for the study. The findings revealed that the investors were satisfied with the initiation of banks, the usefulness of the scheme, and personal benefits, whereas dissatisfied related to the facilities provided to them by the government.

\section{Introduction}

Financial inclusion, otherwise known as 'Inclusive Financing' (Paramasivan and Arunkumar, 2018) is a creative concept initiated by few growing nations, including India. It is a drive taken by the Government of India towards the financial advancement of the oppressed individuals (Hirabai, 2019). It is the quest for making available various financial products and services accessible to financially barred individuals at a reasonable cost. It strives to redress the obstacles that suspend individuals from partaking in the financial sector. Parameters such as banking services availability, banking penetration, and banking services operation are used for estimating financial inclusion (Agrawal, 2018).

Today, India flaunts development extremely fast, yet most of the populace lives underneath the worldwide poverty line. Each country around the globe is focused on the lack of poverty or financial exclusion and attempting to lessen it by various ways or schemes. To eliminate destitutions and give an advantage to the disadvantaged segment of the society, our honorable Prime Minister Shri Narendra Modi has introduced a new financial inclusion scheme and named it 'Pradhan Mantri Jan Dhan Yojana'. 
Before the advent of this scheme, various programs were launch by the earlier government like Swabhiman, Self Help Groups bank linkage program, and the foundation of National Bank for Agriculture and Rural Development, yet failed to achieve the goal for financial inclusion. This plan is launched on a large scale and made Guinness book of world record for 'The maximum number of bank accounts opened in a week' and achieving a sum of 18,096,130 confirmed additional bank accounts opened in between 23rd to 29th August 2014 became extremely famous within a limited period, therefore interest to study the satisfaction level of the account holders has automatically developed toward this (Kumar and Jangid, 2018).

The PMJDY scheme was launch on $15^{\text {th }}$ August 2014 and started its operation on $28^{\text {th }}$ August 2014. The scheme signifies 'Inclusive Growth' (Nimbrayan et al., 2018) has put a pause on corruption enabling the government to directly transfer the subsidies to the PMJDY beneficiaries' account (Goyal and Khera, 2016). The scheme has provided access to banking facilities and services for both rural and urban unbanked households, bank accounts with the facilities of overdraft and RuPay Debit card, Financial Literacy Program to make the individuals financially literate, credit facility, various insurance such as health insurance, accidental insurance, house insurance, etc., as well as pensions to the poor workers (Sandhya, 2017).

\section{Review of Literature}

Kumar and Joseph (2018) attempted to study the customer satisfaction level of the Dindigul district of Tamil Nadu related to the operation of the PMJDY bank account and found that the better operationalization of such an account has created a challenge for the bank employees and the Government authorities. The study found that factors influencing the operation of accounts have directly affected the advertisement made on different features and the economic progress of an individual. Kumar (2018) studied the satisfaction and awareness level among the customers related to the scheme in the Coimbatore District of Tamil Nadu and found a maximum of the respondents were satisfied with the program. Renugadevi and Jeyakodi (2017) analyzed the satisfaction level of customers towards the scheme in Madurai city of Tamil Nadu. Out of 39,000 new bank accounts opened by the people of Madurai district, 37000 bank accounts opened were under the Canara Bank (lead bank of Madurai District). Moreover, account holders have successfully utilized the advantages provided to them and are satisfied with the benefits under the scheme.

Bhuyan (2018) studied the impact of the PMJDY on the banking behavior of account holders in Odisha and found that despite the significant effects on the attitude of the account holders, they lack awareness about credit products. Biju and Aparna (2018) attempted to analyze the perception of the 60 customers and 56 Bank employees in Kerala. The scheme achieved financial inclusion and has created awareness among the rural areas people in inculcating savings habits. Patnaik et al. (2015) studied the awareness level among the people of Bhubaneswar related to the scheme and the satisfaction level related to banking services. A sample size of 137 respondents has considered for which $19 \%$ of male and $7 \%$ female have bank accounts. People of the age group 30-40 have the highest access to bank accounts. The respondents whose income varies in between Rs. 1000-2000 per month do not have access to bank accounts. $97 \%$ of the total respondents (48 respondents for which includes $81 \%$ 
males and $18 \%$ females) with no education do not have access to bank accounts. Poorna and Saravanan (2015) analyzed the perception of the customer of Coonoor Taluk in Nilgiri district and found the scheme successful, used effectively by the general population of Tamil Nadu.

\section{Objective and Hypothesis of the Study}

The objective of the study is to measure the satisfaction level of the PMJDY account holders of Assam Gramin Vikash Bank in Cachar District and to fulfill the same, following hypothesis has constructed:

$\mathrm{H}_{01}$ : There is no significant difference between demographic variables and satisfaction level among the AGVB PMJDY account holders in Cachar District.

\section{Research Methodology}

\subsection{Research Design and Schedule Development}

This paper is based on a survey research design to focus on the demographic overview of the respondents and thereby understand the satisfaction level related to the PMJDY to produce quantitative details of the studied population. An interview schedule has been used for data collection since most people were illiterate in the selected areas and has framed in the following process-

First, the authors have accessed shodhganga and e-journals of eminent publishers through university digital library sources and searched for particular keywords such as financial inclusion, PMJDY, satisfaction level, and then downloaded the pertinent papers for review. Selected papers are review to generate the factors and items to be considered to measure the satisfaction level of the customers.

Second, a protocol interview with 6 experts has carried primarily to check the validity of the questions, and doubts, wherever raised, were clarified. After the discussion, 4 factors based on 18 statements have prepared on five-point Likert scales viz. Highly Satisfied, Satisfied, Neutral, Dissatisfied and Highly Dissatisfied; where 5 indicates 'Highly Satisfied', 4 indicates 'Satisfied', 3 indicates 'Neutral', 2 indicates 'Dissatisfied', and 1 indicates 'Highly Dissatisfied' to measure the satisfaction level of the beneficiaries are retain for the pilot study.

Third, a pilot survey has conducted on 40 beneficiaries (10 beneficiaries from each selected AGVB branch). The schedule framed for the final Survey has pre-tested, and after pre-testing, the sample size has ascertained using 'Macorr Sample Size Calculator' at 95\% confidence level and 6\% confidence interval.

\subsection{Sampling Design and Sample Size}

For the collection of primary data from the account holders, a Multi-Stage Research Design has used. Based on convenient sampling technique, four AGVB Branches viz. AGVB Irongmara Branch (a rural branch), AGVB Dwarbond Branch (a rural branch), AGVB Srikona Branch (a rural branch), and AGVB Silchar Branch (a semi-urban branch) are selected.

The population size under the PMJDY scheme of AGVB in Cachar District was 39,408 as of 28th August 2019, and based on Purposive Sampling technique sample size of 265 respondents (40 respondents from AGVB Silchar Branch, 44 respondents from AGVB Srikona Branch, 102 respondents 
from AGVB Dwarbond Branch, and 79 respondents from AGVB Irongmara branch) are considered further for the collection of data. The sample size formula used is as under-

$$
s s=\frac{Z^{2} * p *(1-p)}{C^{2}}
$$

$Z=Z$ value (e.g. 1.96 for $95 \%$ confidence level)

$\mathrm{P}=$ percentage picking a choice, expressed as decimal (e.g. $0.04= \pm 4$ )

Correction for finite population:

$$
n e w s s=\frac{s s}{1+\frac{s s-1}{p o p}}
$$

Pop $=$ population

Source: (http://www.macorr.com/sample-size-calculator.htm)

The researcher approached the selected branches to collect the PMJDY account holders list, with prior approval from the Department of Commerce, Assam University, and AGVB Regional Office, Silchar, Assam. Each bank managers have provided lists of 110 account holders name, address with their mobile number. The required number of account holders were contacted and were explained the purpose of the visit and requested their humble participation in the study.

Finally, the researcher has gathered details from 265 account holders related to their demographic profile (Gender, Age, and Income level) and duly filled up the interview schedule comprised of 18 items divided into four factors viz. Banks Initiation, Facilities provided under PMJDY, Usefulness of PMJDY and Personal Benefits (Irrinki and Burlakanti, 2017; Deb and Das, 2016; Kumar and Jangid, 2018; Kumar and Joseph, 2018; Renugadevi and Jeyagodi, 2017) which was established primarily from prior studies, filtered by protocol interviews followed by pilot study and subsequently tested through interview schedule.

\subsection{Techniques and Tools Used}

IBM SPSS Statistics Version 21 and MS-Excel Software are used for data analysis. The items are analyzed either through descriptive statistics such as tabulation, graphs, percentages, median value or inferential statistics such as Mann-Whitney U Test \& Kruskal Wallis H Test for testing the hypothesis at a $5 \%$ significance level.

\section{Data Analysis and Findings}

\subsection{Demographic Profile of the Account Holders}

The data are analyzed using various tools such as determining the percentage of the variables of the Demographic Profile of the AGVB Account Holders. The median value of satisfaction level of the AGVB account holders based on each statement divided into four factors are computed and represented through bar graphs. For testing the hypothesis, the Mann-Whitney $\mathrm{U}$ test is used to compare between 
factors of satisfaction level across gender of the account holders and Kruskal Wallis H Test to compare between factors of satisfaction level across the account holders age and income level. The same is interpreted below after each of the tables.

Table 1: Demographic Profile of the Account Holders

\begin{tabular}{|c|c|c|c|c|c|c|c|c|c|c|c|}
\hline \multirow[t]{2}{*}{$\begin{array}{l}\text { Sl. } \\
\text { No }\end{array}$} & \multirow[t]{2}{*}{$\begin{array}{l}\text { Demographic } \\
\text { variables }\end{array}$} & & \multicolumn{2}{|c|}{$\begin{array}{l}\text { AGVB } \\
\text { Silchar }\end{array}$} & \multicolumn{2}{|c|}{$\begin{array}{l}\text { AGVB } \\
\text { Srikona }\end{array}$} & \multicolumn{2}{|c|}{$\begin{array}{c}A G V B \\
\text { Dwarbond }\end{array}$} & \multicolumn{2}{|c|}{$\begin{array}{c}A G V B \\
\text { Irongmara }\end{array}$} & \multirow[b]{2}{*}{$\begin{array}{l}\text { Freq- } \\
\text { uency } \\
\text { Total }\end{array}$} \\
\hline & & & $\begin{array}{l}\text { Freq- } \\
\text { uency }\end{array}$ & $\begin{array}{r}\text { Percen- } \\
\text { tage to } \\
\text { the } \\
\text { total }\end{array}$ & $\begin{array}{l}\text { Freq- } \\
\text { uency }\end{array}$ & $\begin{array}{r}\text { Percen- } \\
\text { tage to } \\
\text { the } \\
\text { total }\end{array}$ & $\begin{array}{l}\text { Freq- } \\
\text { uency }\end{array}$ & $\begin{array}{r}\text { Percen- } \\
\text { tage to } \\
\text { the } \\
\text { total }\end{array}$ & $\begin{array}{l}\text { Freq- } \\
\text { uency }\end{array}$ & $\begin{array}{r}\text { Percen- } \\
\text { tage to } \\
\text { the } \\
\text { total }\end{array}$ & \\
\hline \multirow[t]{2}{*}{1} & Gender & Male & 19 & 07.17 & 17 & 06.42 & 31 & 11.69 & 26 & 09.81 & 93 \\
\hline & & Female & 21 & 07.92 & 27 & 10.19 & 71 & 26.79 & 53 & 20 & 172 \\
\hline \multirow[t]{3}{*}{2} & Age (in & $18-35$ & 19 & 07.17 & 21 & 07.92 & 67 & 25.28 & 51 & 19.25 & 158 \\
\hline & complete & $36-50$ & 13 & 04.91 & 15 & 05.66 & 19 & 07.17 & 15 & 05.66 & 62 \\
\hline & years) & $51-65$ & 08 & 03.02 & 08 & 03.02 & 16 & 06.04 & 13 & 04.91 & 45 \\
\hline \multirow[t]{3}{*}{3} & $\begin{array}{l}\text { Monthly } \\
\text { Income }\end{array}$ & $\begin{array}{l}\text { Below } \\
5000\end{array}$ & 09 & 03.40 & 13 & 04.91 & 45 & 16.98 & 37 & 13.96 & 104 \\
\hline & (in Rs.) & $\begin{array}{l}5001- \\
10000\end{array}$ & 25 & 09.43 & 28 & 10.57 & 45 & 16.98 & 35 & 13.20 & 133 \\
\hline & & $\begin{array}{l}10001 \\
\text { and } \\
\text { above }\end{array}$ & 06 & 02.26 & 03 & 01.13 & 12 & 04.53 & 07 & 02.64 & 28 \\
\hline
\end{tabular}

Source: Survey Data Collected by the Researchers

Table 1 indicates the frequency and percentages of demographic variables (gender, age, and income level) of the respondents and reveals that the female PMJDY account holders are more than the male account holders. The account holders in the age group of 18-35 years are the maximum and the least in the age group 51-65 years. Most of them are having an income level of Rs. 5001 to Rs. 10000 and a few of them earn Rs. 10001 and above.

\subsection{Overall Satisfaction Level of the Account Holders}

The first factor "Banks Initiation" is delineated through five statements 'Bank employees behavior', 'Bank employees assistance while opening the PMJDY account', 'Bank employees assistance in solving your queries related to the scheme', 'Assistance from the bank staff while doing bank transaction', and 'Awareness campaign initiated by the bank related to PMJDY scheme'. The second factor is related to the "Facilities provided under PMJDY" consisting of three statements 'Minimum documents required to open an account', 'Insurance/Pension provided under the scheme', and 'LPG Subsidies provided'. 
The third factor "Usefulness of PMJDY" is represented through three statements 'Introducing Zero Balance Account', 'Easy processing of the scheme' and 'Decreased leakage of funds viz. corruption'. The fourth-factor 'Personal Benefits' are delineated through seven statements such as 'Created a savings habit to fund the future consumption', 'Lessened the unnecessary expenditure', 'Improved the financial literacy', 'Reduced dependency on local money lenders', 'Improved the usage of money', 'Reduced the poverty' and 'Helped in mobilizing deposit in a secured manner'. The median value is used to interpret the overall satisfaction level related to the PMJDY account holders.

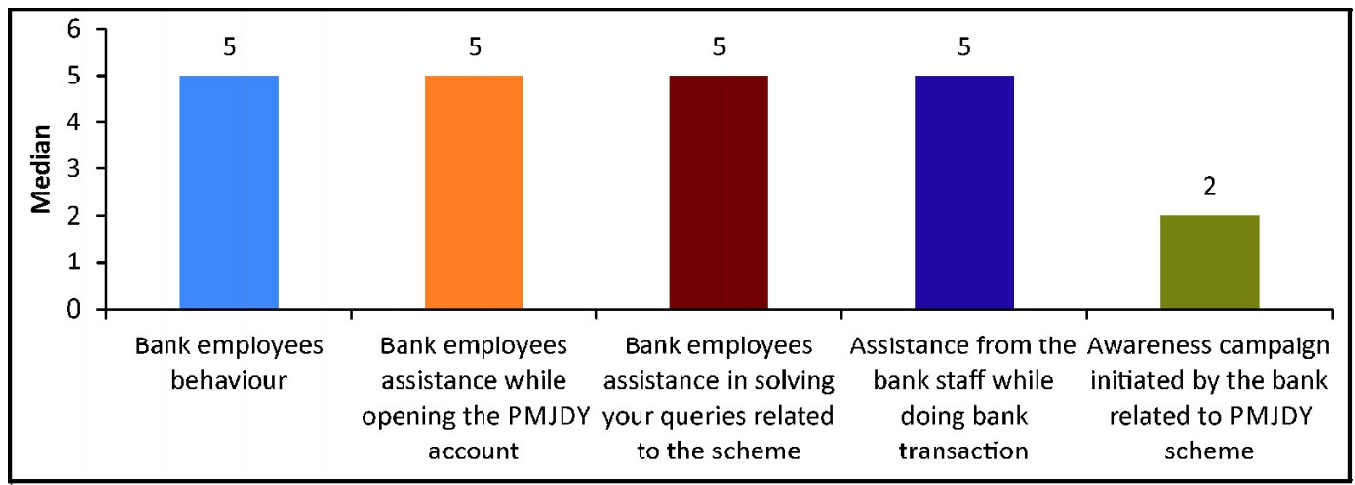

Figure 1: Median Value of the Statements for the Factor 'Banks Initiation'

Source: Compiled from Survey Data

Figure 1 shows that out of the five statements over the factor 'Banks Initiation' the account holders are highly satisfied over the behavior of bank employees, the assistances provided while opening the accounts, solving queries of the customers, and while doing banking transactions whereas dissatisfied related to the awareness campaign initiated by the banks.

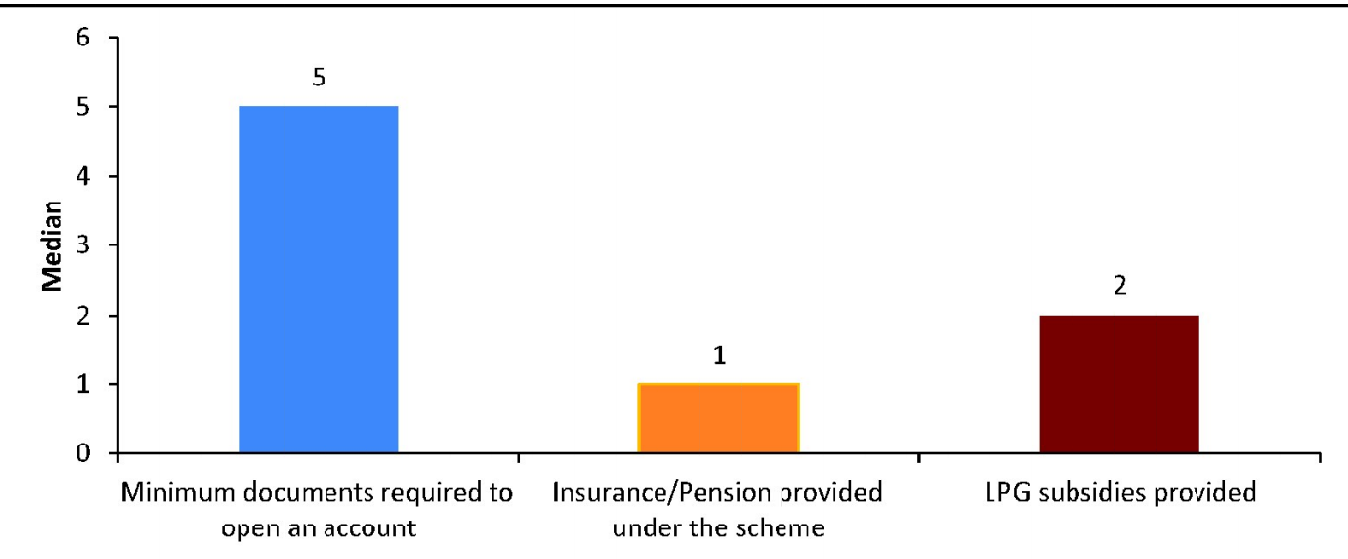

Figure 2: Median Value of the Statements for the Factor 'Facilities Provided under PMJDY'

Source: Compiled from Survey Data 
Figure 2 reveals that, out of the three statements over the factor 'Facilities provided under PMJDY', the account holders are highly satisfied with the requirement of minimum documents to open an account whereas highly dissatisfied with the provision of Insurance/Pension provided and dissatisfied with the LPG subsidies provided.

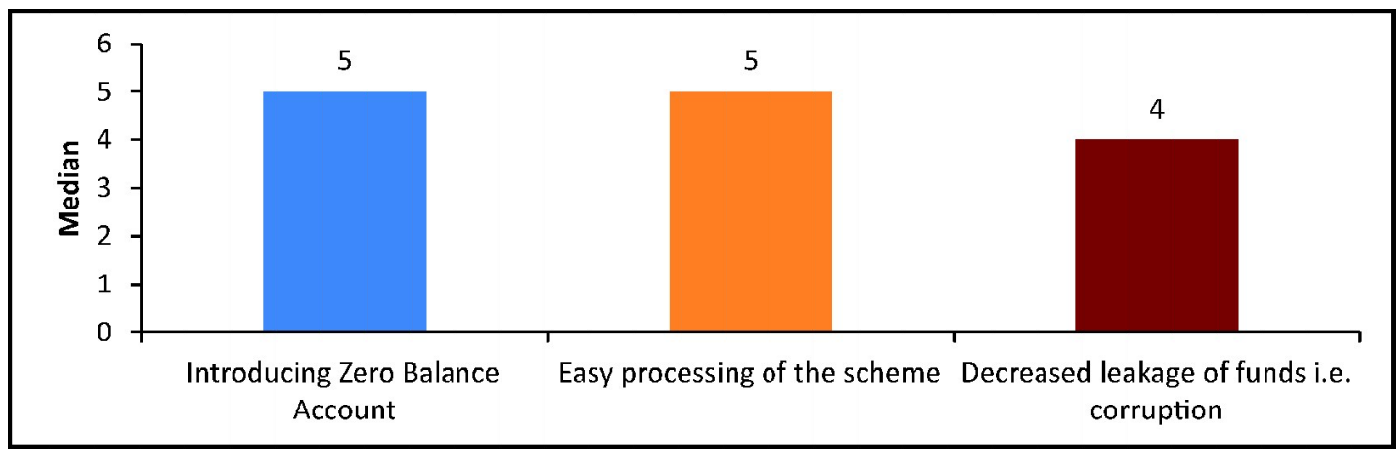

Figure 3: Median Value of the Statements for the Factor 'Usefulness of PMJDY'

Source: Compiled from Survey Data

Figure 3 highlights that, out of the three statements over the factor 'Usefulness of PMJDY' the account holders are highly satisfied with the Introduction of Zero balance account and its easy processing but are only satisfied with the decrease of corruption.

Figure 4 indicates that out of the seven statements over the factor 'Personal Benefits', the account holders are highly satisfied with the savings habit to fund their future consumption and have reduced dependency on local money lenders. They are Satisfied over the statements lessening their unnecessary

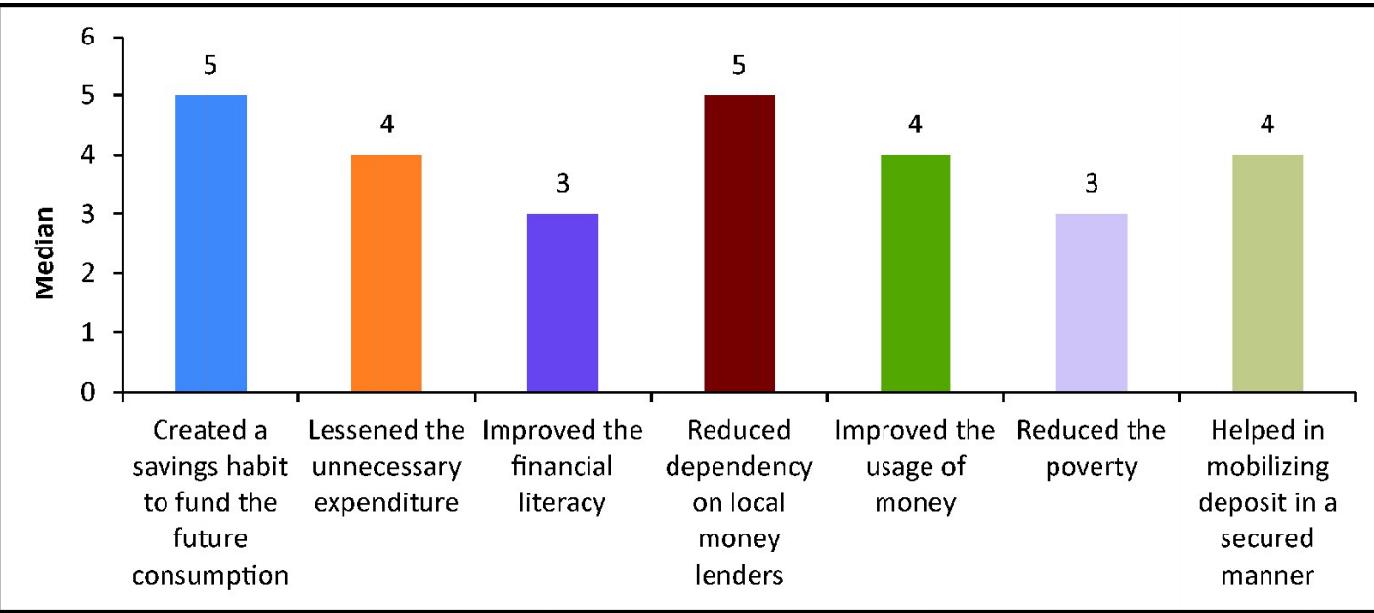

Figure 4: Median Value of the Statements for the Factor 'Personal Benefits'

Source: Compiled from Survey Data 
Sudeepta Raha and Parag Shil

expenditures, improving the usage of money, helping them Securely mobilize deposits but are neutral (neither satisfied nor dissatisfied) towards the Statements improving their financial literacy and reducing their poverty.

Table 2: Overall Satisfaction Level based on Different Factors

\begin{tabular}{lcl}
\hline Factors & Value & Satisfaction Level \\
\hline Banks initiation & 5 & Highly Satisfied \\
Facilities provided under PMJDY & 2 & Dissatisfied \\
Usefulness of PMJDY & 5 & Highly Satisfied \\
Personal Benefits & 4 & Satisfied \\
\hline
\end{tabular}

Source: Compiled from Survey Data

From Table 2 it can be inferred that out of the four factors considered in the study, 'Banks initiation' and 'Usefulness of PMJDY' are perceived as the most important factor for determining the satisfaction level of PMJDY account holders of AGVB in the Cachar District followed by 'Personal Benefits'. Investors are dissatisfied over the factor 'Facilities provided under PMJDY' indicating that the AGVB account holders are not receiving adequate benefits provided by the government.

\subsection{Comparison of Different Factors of Satisfaction Level Across Various Demographic Variables}

The data is not following normal distribution, therefore the Mann-Whitney $U$ test is used to compare different factors of satisfaction level across gender level of the PMJDY account holders, and the Kruskal Wallis $\mathrm{H}$ test is used for the age group and income level of the respondents.

Table 3: Mann-Whitney U Test on Different Factors Grouped by the Gender of the Respondents

\begin{tabular}{lccc}
\hline Factors & U Value & p value & Not significant/ Significant \\
\hline Banks initiation & 7628.500 & 0.528 & Not significant \\
Facilities provided under PMJDY & 7514.000 & 0.404 & Not significant \\
Usefulness of PMJDY & 7168.000 & 0.156 & Not significant \\
Personal Benefits & 6811.500 & 0.043 & Significant \\
\hline
\end{tabular}

Source: Compiled from Survey Data

The results of the U-test (Table 3) at a 5\% level of significance over the factors Banks Initiation $[\mathrm{p}=0.528]$, Facilities provided under PMJDY [ $\mathrm{p}=0.404]$, and Usefulness of PMJDY $[\mathrm{p}=0.156]$ are having $\mathrm{p}$-values more than 0.05 results to the acceptance of $\mathrm{H}_{01}$, which implies that there is no significant difference of PMJDY satisfaction level between male and female respondents, and the corresponding 
Study on the Satisfaction Level of the Account Holders under Pradhan Mantri Jan Dhan Yojana Scheme

p-value for Personal Benefits is $0.043<0.05$ resulting to the rejection of $\mathrm{H}_{01}$, which signifies gender difference exists over the factor.

Table 4: Kruskal Wallis H Test on Different Factors Grouped by the Age of the Respondents

\begin{tabular}{lccc}
\hline Factors & H value $(\text { Chi-Square })^{2 d f}$ & p value & Not significant/ Significant \\
\hline Banks initiation & 6.121 & 0.047 & Significant \\
Facilities provided under PMJDY & 3.374 & 0.185 & Not significant \\
Usefulness of PMJDY & 9.690 & 0.008 & Significant \\
Personal Benefits & 3.203 & 0.202 & Not significant \\
\hline
\end{tabular}

Source: Compiled from Survey Data

The results of the H-test (Table 4) at 5\% level of significance over the factors Facilities provided under PMJDY [ $\mathrm{p}=0.185]$, and Personal Benefits [ $\mathrm{p}=0.202]$ are having $\mathrm{p}$-values more than 0.05 results to the acceptance of $\mathrm{H}_{01}$, which implies that there is no significant difference of PMJDY satisfaction level across the age groups of the respondents, whereas the corresponding $\mathrm{p}$-value over the factor Banks Initiation is 0.047 and Usefulness of PMJDY is $0.008<0.05$ which implies that there is a significant difference of PMJDY satisfaction level across the respondents' age groups.

Table 5: Kruskal Wallis $\mathbf{H}$ Test on different factors grouped by the Monthly Income of the Respondents

\begin{tabular}{lccc}
\hline Factors & ${\text { (Chi-Square Value) })^{2}}^{\text {df }}$ & p value & Not significant/ Significant \\
\hline Banks initiation & 0.117 & 0.943 & Not significant \\
Facilities provided under PMJDY & 10.371 & 0.006 & Significant \\
Usefulness of PMJDY & 5.976 & 0.050 & Significant \\
Personal Benefits & 11.666 & 0.003 & Significant \\
\hline
\end{tabular}

Source: Compiled from Survey Data

The p-value of the H-test (Table 5) at 5\% level of significance over the factors Banks Initiation is $0.943>0.05$ result to the acceptance of $\mathrm{H}_{01}$, which reveals that the satisfaction level of the PMJDY account holders across their income level is not significantly different whereas the corresponding $\mathrm{p}-$ value over the factors Facilities provided under PMJDY [ $\mathrm{p}=0.006]$, Usefulness of PMJDY [ $\mathrm{p}=0.05]$ and Personal Benefits $[\mathrm{p}=0.003]$ are less than 0.05 which implies the satisfaction level varies significantly across the respondents' income level.

\section{Conclusion}

This study is conducted to understand the satisfaction level of the PMJDY account holders towards the implementation of the scheme. As per the Census of India 2011, Cachar District has population of $1,736,617$ of which 315,464 people (i.e. $18.17 \%$ ) lives in urban areas and 1,421,153 people (i.e. $81.83 \%$ ) lives in rural areas. People living in rural areas of the Cachar district are significantly higher than the people living in urban areas. Investors are satisfied with the banking services, usefulness 
provided under the scheme, and personal benefits; however, dissatisfied in the case of special benefits provided by the government. Although the PMJDY scheme provides numerous facilities to the underprivileged, this study found minimum respondents received the facilities provided by the government but highly disgraceful that AGVB PMJDY account holders in the Cachar District of Assam have not received any assistance after opening accounts. There must be linkages between the Aadhar card and the PMJDY accounts to receive the direct benefit transfer provided by the government (Direct Benefit Transfer, Government of India, 2021) however the registration process for the Aadhar card is still pending for most of the populace of Assam as the State Government is willing to amend the National Register of Citizens (NRC) initially. The coverage of the samples taken for the study is confining to four AGVB Branches of Cachar District. The scope of the study is limited to its sample size, period and variables undertaken; however, future studies can deal to broaden the scope of analysis.

\section{References}

Agrawal, N. (2018). A study of the extent of financial literacy regarding Pradhan Mantri Jan Dhan Yojana. Retrieved from http://hdl.handle.net/10603/230272

Bhuyan, M. (2018). A Study on Banking Behavior of Account Holders under Pradhan Mantri Jan Dhan Yojana (PMJDY). Retrieved from http://hdl_handle_net $\angle 10603 \angle 230272$

Biju, M. K., \& Aparna, M. (2018). Financial Inclusion- A study on the opinions of customers and employees of banks in Kerala, International Journal of Research in Economics and Social Sciences (IJRESS), 8(10), 1-10.

Deb, R., \& Das, P. (2016). Perceptions of bank account holders about PMJDY- A study on Baikhora Region of South Tripura, Amity Journal of Finance, 1(1), 67-91.

Direct Benefit Transfer, Government of India. (2013). Retrieved from wnw.pmjdy.gov.in

Goyal, M., \& Khera, M. (2016). Pradhan Mantri Jan Dhan Yojana: A step towards Financial Inclusion, Pacific Business Review International, 8(9), 130-137.

Hirabai, N. R. S. (2019). Study of Jan Dhan Yojana as an attempt of financial inclusion with reference to specific blocks of Thane district. Retrieved from bttp:// bdl.handle.net/10603/273028

Irrinki, M. K., \& Burlakanti, K. (2017). Perception on PMJDY- A study with reference to Thallarevu Mandal, International Journal of Research - Granthaalayah, 5(6), 129-146.

Kumar, D. R. (2018). A study on Pradhan Mantri Jan Dhan Yojana awareness and its satisfaction- A Financial Inclusion initiative (With special reference to Coimbatore District), International Journal of Research and Analytical Reviens, 5(3), 104-106.

Kumar, R. M. \& Joseph, C. S. (2018). Customer satisfaction in operation of Pradhan Mantri Jan Dhan Yojana (PMJDY) Account: An empirical evidence, International Journal of Management Studies, V, 2(5), 29-35.

Kumar, S. \& Jangid, V. (2018). Financial Inclusion through Pradhan Mantri Jan Dhan Yojana: Customer's view point, International Journal of 360 Management Review, 2(2), 1-8.

Nimbrayan, P. K., Tripathi, R., \&Tanwar, N. (2018). PMJDY: The Biggest Financial Inclusion Initiative in the World, Economic Affairs, 63(2), 583-590.

Paramasivan, C., \& Arunkumar, G. (2018). Direct Benefit Transfer- An Innovative approach to Financial Inclusion in India, Journal of Emerging Technologies and Innovative Approach (JETIR), 5(12), 409-418.

Patnaik, B. C. M., Satpathy, I., \& Supkar, A. C. (2015). Pradhan Mantri Jan Dhan Yojana (PMJDY) - A new direction for mainstreaming the financially excluded, International Journal of Management (IJM), 6(2), 31-42. 
Study on the Satisfaction Level of the Account Holders under Pradhan Mantri Jan Dhan Yojana Scheme

Poorna, K., \& Saravanan, S. (2015). A Study on Pradhan Mantri Jan Dhan Yojana Scheme (PMJDY) with respect to Coonoor Taluk, The Nilgiris District: Customer Perception, IJSR - International Journal of Scientific Research, 4(3), 54-56.

Renugadevi, S. \& Jeyagodi, K. (2017). A study on customers' level of satisfaction towards Pradhan Mantri Jan Dhan Yojana scheme with reference to Madurai city, International Journal of Current Research and Modern Education (IJCRME), 2(1), 18-22.

Sandhya, P. (2017). Reinventing Financial Inclusion through PMJDY, Amal International Journal of Economics and Social Sciences, 2(3), 55-62.

Orissa Journal of Commerce, 42(1) (C) 2021 